\section{(2) OPEN ACCESS}

\title{
Association between COPD exacerbations and lung function decline during maintenance therapy
}

\author{
Marjan Kerkhof, ${ }^{1}$ Jaco Voorham, ${ }^{1}$ Paul Dorinsky, ${ }^{2}$ Claudia Cabrera, ${ }^{3,4}$ Patrick Darken, ${ }^{5}$ \\ Janwillem WH Kocks, ${ }^{1,6}$ Mohsen Sadatsafavi (D) , ${ }^{7}$ Don D Sin, ${ }^{7,8}$ Victoria Carter, ${ }^{1}$ \\ David B Price (D) 1,9
}

\begin{abstract}
- Additional material is published online only. To view please visit the journal online (http://dx.doi.org/10.1136/ thoraxjnl-2019-214457).
\end{abstract}

For numbered affiliations see end of article.

\section{Correspondence to} Professor David B Price, Academic Primary Care, University of Aberdeen, Aberdeen AB25 2ZD, UK; dprice@oprisg

Received 16 December 2019 Revised 28 April 2020 Accepted 7 May 2020 Published Online First 12 June 2020

\section{Linked}

- http://dx.doi.org/10.1136/ thoraxjnl-2020-214821

Check for updates

(C) Author(s) (or their employer(s)) 2020. Re-use permitted under CC BY-NC. No commercial re-use. See rights and permissions. Published by BMJ.

To cite: Kerkhof $\mathrm{M}$, Voorham J, Dorinsky P, et al. Thorax 2020;75:744-753.

\begin{abstract}
Background Little is known about the impact of exacerbations on COPD progression or whether inhaled corticosteroid (ICS) use and blood eosinophil count (BEC) affect progression. We aimed to assess this in a prospective observational study.

Methods The study population included patients with mild to moderate COPD, aged $\geq 35$ years, with a smoking history, who were followed up for $\geq 3$ years from first to last spirometry recording using two large UK electronic medical record databases: Clinical Practice Research Datalink (CPRD) and Optimum Patient Care Research Database (OPCRD). Multilevel mixed-effects linear regression models were used to determine the relationship between annual exacerbation rate following initiation of therapy (ICS vs non-ICS) and FEV , decline. Effect modification by blood eosinophils was studied through interaction terms.

Results Of 12178 patients included (mean age 66 years; 48\% female), 8981 (74\%) received ICS. In patients with $\mathrm{BEC} \geq 350$ cells/ $\mu \mathrm{L}$ not on ICS, each exacerbation was associated with subsequent acceleration of FEV decline of $19.4 \mathrm{~mL} /$ year $(95 \% \mathrm{Cl} 12.0$ to 26.7 , $\mathrm{p}<0.0001)$. This excess decline was reduced by $15.1 \mathrm{~mL}$ year (6.6 to 23.6 ) to $4.3 \mathrm{~mL} /$ year (1.9 to $6.7, p<0.0001$ ) in those with $\mathrm{BEC} \geq 350 \mathrm{cell} / \mathrm{sL}$ treated with ICS.

Conclusion Exacerbations are associated with a more

\section{Key messages}

What is the key question?

- We aimed to assess whether chronic obstructive pulmonary disease (COPD) exacerbations occurring under maintenance therapy, earlier on in the life cycle of COPD, are associated with accelerated subsequent lung function decline and whether the blood eosinophil count (BEC) is a biomarker for risk stratification.

What is the bottom line?

- This study provides novel and important evidence that exacerbations occurring in patients with mild to moderate COPD who demonstrate elevated blood eosinophils are associated with rapid lung function loss, and that receiving inhaled corticosteroid (ICS) in these patients is associated with significant mitigation of lung function decline.

Why read on?

- This study addresses the importance of recognising the need for ICS treatment to prevent rapid lung function loss associated with exacerbations in patients who demonstrate high BECs in daily clinical practice.
\end{abstract} rapid loss of lung function among COPD patients with elevated blood eosinophils, defined as $\geq 350$ cells $/ \mu L$, not treated with ICS. More aggressive prevention of exacerbations using ICS in such patients may prevent excess loss of lung function.

\section{INTRODUCTION}

COPD is a progressive respiratory condition characterised by non-reversible airflow limitation. ${ }^{1}$ In approximately half of patients, COPD results from accelerated lung function decline following normal lung growth and development during childhood and adolescence. ${ }^{23}$ Lung function decline is most accelerated in mild to moderate disease and can occur prior to a clinical diagnosis of COPD. For example, Tantucci et al reviewed spirometric data from patients with COPD in the placebo arms of clinical trials and found that lung function decline was most accelerated in the initial phases of COPD (GOLD stage II). ${ }^{4}$ A recent study by Bhatt et al confirmed that in a population of current and former smokers, the rate of $\mathrm{FEV}_{1}$ decline was greatest in mild COPD. ${ }^{5}$ Thus, evaluating individuals at an earlier stage before they have lost much of their lung function is important in assessing treatment effectiveness.

Good adherence to maintenance therapy from the early stages of disease onwards may slow disease progression. Treatment with inhaled corticosteroids (ICS) may prevent structural changes in the lung associated with COPD exacerbations. ${ }^{6}$ It has been demonstrated that patients who suffer recurrent exacerbations have increased concentrations of inflammatory markers in their sputum. ${ }^{7}$ This suggests that the presence of persistent inflammation may underlie COPD disease progression. ${ }^{89}$ However, recent clinical trials have demonstrated only modest effects of maintenance inhalation therapy on reduction of lung function decline in patients with COPD. ${ }^{10}{ }^{11}$ Thus, questions remain as to whether inflammation or other factors are linked to COPD disease progression and whether these can be modified by treatment.

Acute exacerbations have been associated with accelerated lung function decline, particularly 


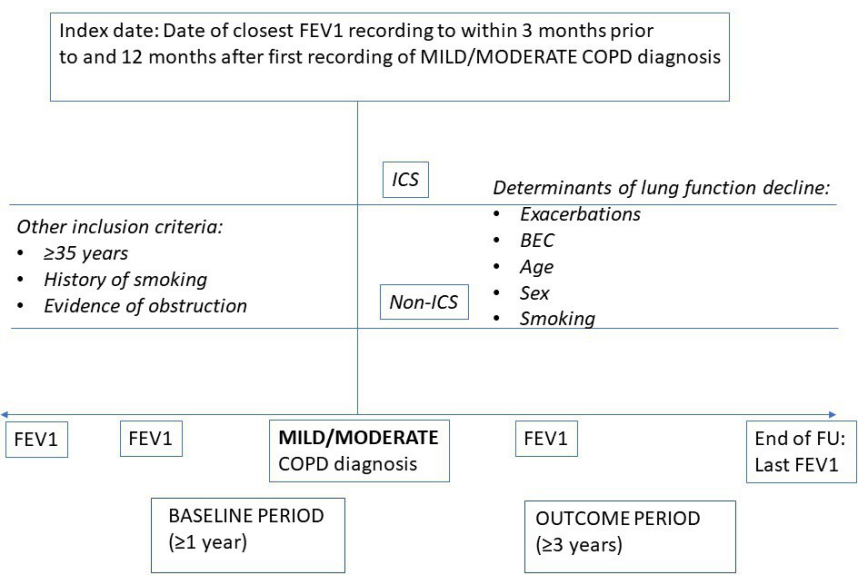

Figure 1 Study design. BEC, blood eosinophil count; FU, follow-up; ICS, inhaled corticosteroid.

in those with mild disease (GOLD stage I). ${ }^{12}{ }^{13}$ It is unknown whether ICS treatment is effective in preventing this potential damage to the lungs associated with exacerbations. Additionally, blood eosinophils are known to predict the risk of future events and response to ICS in terms of exacerbation prevention and improvement in lung function. Patients with a high blood eosinophil count (BEC) were found to be most responsive to treatment with ICS. ${ }^{14-18}$ It is however unknown whether BECs could be a good biomarker to identify patients who would benefit from ICS in terms of slowing lung function decline at earlier stages of disease development. This has been suggested by a post hoc analysis of a small group of clinical trial patients with more advanced COPD. ${ }^{19}$ We aimed to assess whether COPD exacerbations occurring under maintenance therapy, earlier on in the life cycle of COPD, are associated with accelerated subsequent lung function decline and whether the BEC is a biomarker for risk stratification.

\section{METHODS}

\section{Study design and data sources}

A prospective observational study was carried out among patients with COPD in the UK (figure 1). Primary care data were extracted from the Clinical Practice Research Datalink (CPRD; http://www.cprd.com/) and Optimum Patient Care Research Database (OPCRD; https://opcrd.co.uk/). Further details of these data sources are provided in the online supplementary. Clinical data are recorded using Read codes; the codes used for COPD were those within the Quality and Outcomes Framework (QOF) and the diagnosis has been validated. ${ }^{20} 21$ Practices who contributed to both CPRD and OPCRD and had $\geq 60 \%$ overlap in patient age, gender and index date (defined below) were assumed to be the same, and thus patient records from the OPCRD dataset for that practice were removed as duplicate when the datasets were merged.

\section{Study population}

This study included patients diagnosed with mild to moderate COPD $\left(\mathrm{FEV}_{1} \%\right.$ predicted $\geq 50 \%$ and $\left.\leq 90 \%\right)$ at age $\geq 35$ years, who had a history of tobacco smoking and evidence of obstruction ever recorded. Patients with active asthma at or after the date of the first COPD diagnosis were excluded, as were those with $<3$ years of spirometry follow-up. Further details regarding inclusion and exclusion criteria are presented in table 1. All Read code lists are available on request.
Table 1 Inclusion and exclusion criteria for study population

\begin{tabular}{|c|c|c|}
\hline & & teria \\
\hline \multirow[t]{9}{*}{ Inclusion } & $>$ & Diagnostic Read code for COPD \\
\hline & & Age $\geq 35$ years \\
\hline & & $\begin{array}{l}\text { Spirometry recorded between } 3 \text { months before and } 12 \text { months after } \\
\text { the first COPD diagnostic code (index date) }\end{array}$ \\
\hline & & Evidence of obstruction ever recorded $\left(\mathrm{FEV}_{1} / \mathrm{FVC}<0.7\right)$ \\
\hline & & $\begin{array}{l}\text { Mild to moderate airflow limitation ( } \mathrm{FEV}_{1} \% \text { predicted } \geq 50 \% \text { and } \\
\leq 90 \% \text { at index date) }\end{array}$ \\
\hline & & $\begin{array}{l}\geq 1 \text { year of up-to-standard* medical records prior to index date to } \\
\text { enable baseline characterisation }\end{array}$ \\
\hline & & $\begin{array}{l}\text { History of smoking tobacco prior to first COPD diagnosis or at first } \\
\text { recording after diagnosis }\end{array}$ \\
\hline & & $\begin{array}{l}\text { Height at adult age ( } \geq 21 \text { years) and weight recorded within } 5 \text { years } \\
\text { of index date }\end{array}$ \\
\hline & $>$ & $\begin{array}{l}\text { Up-to-standard* follow-up period covering } \geq 3 \text { years between the } \\
\text { first and last spirometry records }\end{array}$ \\
\hline \multirow[t]{3}{*}{ Exclusion } & $>$ & $\begin{array}{l}\text { Active asthma at or after the date of first COPD diagnosis, defined } \\
\text { as } \geq 1 \text { diagnostic Read code for asthma or } \geq 1 \text { asthma monitoring or } \\
\text { review codes recorded, or asthma-COPD overlap syndrome as first } \\
\text { COPD diagnostic code or recorded during follow-up }\end{array}$ \\
\hline & & $\begin{array}{l}\text { Diagnostic code for other chronic lower respiratory conditions ever } \\
\text { recorded }\end{array}$ \\
\hline & & $\begin{array}{l}\text { Severe aiflow limitation ( } \mathrm{FEV}_{1} \% \text { predicted }<50 \% \text { at index date) as } \\
\text { there is limited scope for further } \mathrm{FEV}_{1} \text { decline and early intervention } \\
\text { in these patients }\end{array}$ \\
\hline
\end{tabular}

*Up-to-standard data are of continuous high quality and considered suitable for research.

\section{Data collection and study variables}

The index date was the date of the $\mathrm{FEV}_{1}$ recording closest to 3 months before to 12 months after the first COPD diagnosis. Data on demographics, clinical characteristics and comorbidities were collected at baseline ( 1 year prior to index date) for included patients. The primary outcome was decline in FEV (mL/year) during follow-up (from first to last $\mathrm{FEV}_{1}$ recording). The exposures of interest (see table 2 for detailed definitions and categorisation) included the highest level of maintenance therapy, annual exacerbation rates, BEC and adherence to maintenance therapy.

\section{Data analyses}

All analyses were carried out in Stata V.14.2 (StataCorp, College Station, Texas, USA). Summary descriptive statistics were computed using proportions for categorical variables and means (with SD) and medians (with IQR) for continuous variables. The standardised mean difference (SMD) was used to quantify differences in baseline variables between patients who initiated maintenance therapy with or without ICS and subpopulations of patients who had BEC available $(<50,50-349, \geq 350$ cells/ $\mu \mathrm{L})$. An SMD of $<10 \%$ indicated sufficient balance between the groups. Blood eosinophil values were mostly recorded as $10^{9} / \mathrm{L}$ to one decimal place in electronic medical records. A value of $0.3 \times 10^{9} / \mathrm{L}$ could fall anywhere between 250 and 349 cells $/ \mu \mathrm{L}$. Thus, it is unknown whether such a value is below or above the recommended cut-off point of 300 cells $/ \mu \mathrm{L}$. Cut-off points of 250,350 and 450 cells $/ \mu \mathrm{L}$ were therefore considered in the analyses, with 350 as the primary cut-off point.

A multilevel 'random-slope/random-intercept' model was used to model $\mathrm{FEV}_{1}$ change over time. Fixed effects with $95 \% \mathrm{CI}$ were estimated for the association between annual exacerbation 
Table 2 Variable definitions and categorisation

\begin{tabular}{|c|c|}
\hline Variables & Definitions \\
\hline \multirow[t]{2}{*}{$\begin{array}{l}\text { Highest level of maintenance therapy } \\
\text { (ICS, non-ICS) }\end{array}$} & $\begin{array}{l}\text { Therapy prescribed for at least } 1 \text { year (as separate overlapping prescriptions or as fixed dose combinations) from } 1 \text { year } \\
\text { prior to the first FEV } 1 \text { recording to the last FEV, recording }\end{array}$ \\
\hline & $\begin{array}{l}\text { Ordered from lowest to highest as long-acting bronchodilator only, ICS monotherapy, ICS+LABD, LAMA+LABA and triple } \\
\text { therapy (ICS+LAMA+ LABA), and then grouped into ICS or non-ICS }\end{array}$ \\
\hline \multirow[t]{3}{*}{ Annual exacerbation rate } & $\begin{array}{l}\text { Exacerbations occurring after initiation of the highest level of maintenance therapy until the last FEV } \text { recording were }_{1} \\
\text { counted and divided by the total time of follow-up (days/365) }\end{array}$ \\
\hline & $\begin{array}{l}\text { COPD exacerbation was defined as occurrence of any of the following events: respiratory-related hospital attendance/ } \\
\text { admission; respiratory-related emergency room attendance; prescription of acute OCS course; and/or antibiotics } \\
\text { prescribed with evidence of lower respiratory consultation on the same day }\end{array}$ \\
\hline & Events occurring within 14 days of each other were considered the same exacerbation \\
\hline \multirow{3}{*}{$\begin{array}{l}\text { Blood eosinophil count } \\
(<50,50-349, \geq 350 \text { cells } / \mu \mathrm{L})\end{array}$} & Recorded within a maximum 2 year period before or after date of therapy initiation \\
\hline & Counts measured within 14 days following an OCS prescription were excluded \\
\hline & Cut-off values 250 and 450 cells/ $\mu \mathrm{L}$ also considered \\
\hline \multirow[t]{2}{*}{$\begin{array}{l}\text { Overall adherence to maintenance therapy } \\
(<50 \%, 50 \%-79 \%, 80 \%-100 \%,>100 \%)\end{array}$} & $\begin{array}{l}\text { Calculated as the ratio of total time covered by prescriptions of maintenance inhalers (all types, not only highest level) } \\
\text { and the total duration of follow-up from maintenance therapy initiation to the last FEV, recording }\end{array}$ \\
\hline & $\begin{array}{l}\text { Time covered by one inhaler assumed to be } 30 \text { days for all inhalers, except for ICS single inhalers for which } 50 \text { days was } \\
\text { assumed }\end{array}$ \\
\hline
\end{tabular}

ICS, inhaled corticosteroid; LABA, long-acting beta-agonists; LABD, long-acting bronchodilator; LAMA, long-acting muscarinic antagonist; OCS, oral corticosteroids.

rate after initiation of the highest maintenance therapy (continuous variable) and $\mathrm{FEV}_{1}$ decline, stratified by therapy level during follow-up. The intercept of the model was the baseline $\mathrm{FEV}_{1}$ at first diagnosis. An interaction term of follow-up time with the annual exacerbation rate represented the association of exposure with slope of $\mathrm{FEV}_{1}$ decline. Random effects were included, allowing each patient's change in lung function over time to be scattered around the population average trajectory, assuming that the errors were independent and normally distributed. The model also included sex, age, height, weight and smoking status as covariates, including an interaction term with time, to adjust for potential confounding by other well-known risk factors of lung function decline. All recorded $\mathrm{FEV}_{1}$ values, including values recorded prior to index date, were analysed as the outcome. Differences in associations between groups,

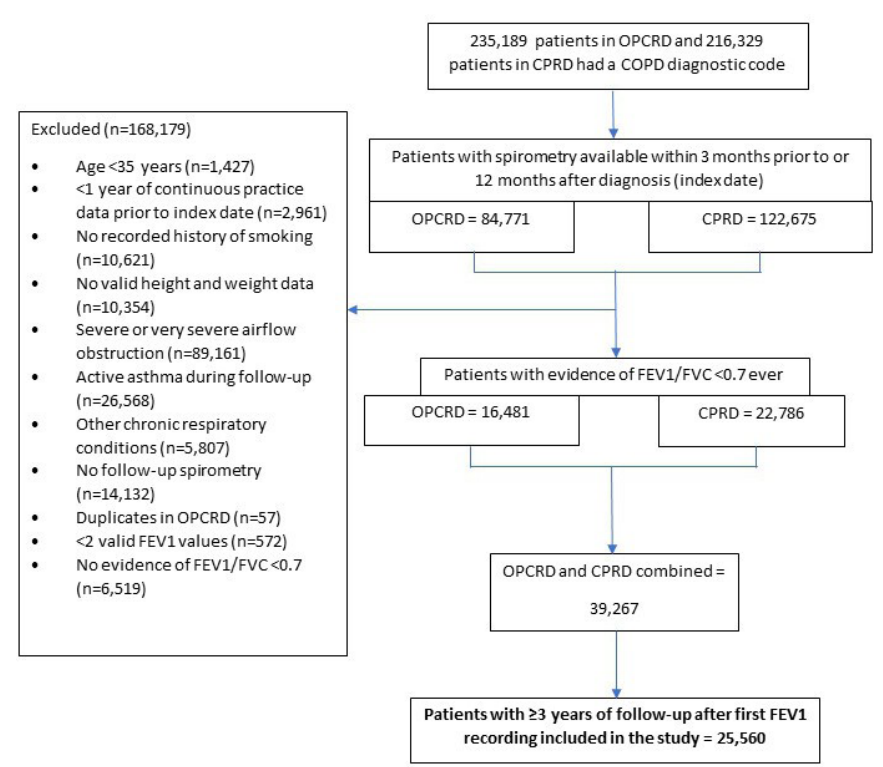

Figure 2 Flow diagram of patient selection. CPRD, Clinical Practice Research Datalink; OPCRD, Optimum Patient Care Research Database. defined by BEC, were statistically tested through interaction terms. CIs of reported differences in associations between both strata of patients with and without ICS therapy were estimated from a model including interaction terms, stratified by eosinophil count. Marginal $\mathrm{FEV}_{1}$ decline with 95\% CIs were visualised at mean exacerbation rates of $0-3$, while covariates were held at their mean value from models stratified by therapy, including interaction terms for blood eosinophil categories. Overall adherence to maintenance therapy (in general), calculated as the percentage of total follow-up time after initiation of maintenance therapy that was covered by inhaler prescriptions, was added to the model to assess its association with lung function decline (table 2). The following two sensitivity analyses were conducted: (1) excluding all patients ever diagnosed with asthma due to potential misclassification between COPD and asthma, and (2) including only patients with at least five $\mathrm{FEV}_{1}$ measurements to assess the impact of less accurate estimates of lung function decline in patients with few measurements.

\section{Role of funding source}

The funders of the study participated in the study design. All authors, including those employed by the funders of the study, participated in the data interpretation and writing of the report. All authors had full access to study results and had final responsibility for the decision to submit for publication.

\section{RESULTS \\ Study population}

A total of 25560 patients with at least 3 years of follow-up (median 6.2; IQR 4.5-8.5) after the first FEV 1 recording were included in the study (figure 2). Patients had a median of six (IQR 4-8) $\mathrm{FEV}_{1}$ recordings; $72 \%$ of patients had at least five recordings, while only $2.4 \%$ had two recordings available. The median index year for these patients was 2008 (IQR 2006-2010).

Among patients who initiated maintenance therapy $(n=19439), 51 \%$ achieved the highest level of therapy within 1 year after baseline spirometry (median number of days: 336 (IQR 0-1089)). The median duration of spirometry follow-up 
after initiation of the highest level of therapy was 4 years (1442 days (IQR 978-2088)) and was less than 1 year in only 1\% of patients (minimum 177 days). Three-quarters of those who initiated maintenance therapy $(\mathrm{n}=14572)$ were treated with ICS and $4867(25.0 \%)$ without ICS as the highest level of therapy during follow-up. Triple therapy (ICS + LAMA+ LABA) was prescribed to $6816(35 \%)$ patients.

Almost $63 \%$ of those who initiated maintenance therapy (12178/19439) had BECs available. Half of the BECs were recorded within 6 months of highest therapy initiation and $82 \%$ within 1 year (median $=129$ days; IQR $=44-291$ ). BEC was available for $8981(62 \%)$ patients who initiated ICS and 3197 (66\%) patients who initiated non-ICS containing therapy as the highest level of maintenance therapy. There was a similar proportion of patients with eosinopenia $(<50$ cells $/ \mu \mathrm{L})$ in both groups (304 (3.4\%) in ICS vs 110 (3.4\%) in non-ICS). A higher proportion of patients in the ICS-containing therapy group had a high BEC compared with patients in the non-ICS containing therapy group. In the ICS group, $20.6 \%(\mathrm{n}=1849)$ and $11.1 \%$ $(\mathrm{n}=993)$ had BEC of $\geq 350$ and $\geq 450$ cells $/ \mu \mathrm{L}$, respectively, compared with $17.0 \%(\mathrm{n}=543)$ and $7.6 \%(\mathrm{n}=243)$ in the nonICS group.

\section{Patient characteristics}

Characteristics of patients treated with or without ICS as the highest level of therapy during follow-up are presented in table 3. Patients treated with ICS had longer follow-up, higher modified Medical Research Council (mMRC) scores and more severe disease (GOLD group). They also experienced more exacerbations in the year prior to the first COPD diagnosis, the year prior to initiation of the highest therapy,and during follow-up after initiation. A higher proportion of patients on ICS had a previous diagnosis of asthma. The presence of other comorbidities was similar between groups (SMD $<10 \%$; see online supplementary table $\mathrm{S} 1$ in online supplementary).

Of 12178 patients with BEC recorded closest to initiation of the highest level of maintenance therapy, $414(3.4 \%)$ had $<50$, $9372(77.0 \%)$ had $50-349$ and 2392 (19.6\%) had $\geq 350$ cells/ $\mu \mathrm{L}$. Demographic and clinical characteristics for these patient groups are presented in table 4 . Patients with high BECs ( $\geq 350$ cells $/ \mu \mathrm{L})$ were more frequently male, more often had a previous diagnosis of nasal polyps and had higher rates of exacerbations. Patients with eosinopenia $(<50$ cells $/ \mu \mathrm{L})$ had a relatively low BMI, more often a diagnosis of osteoporosis, received more prescriptions for oral corticosteroids (OCS), had higher mMRC scores and consulted their general practitioner (GP) more frequently for reasons other than COPD. Further patient characteristics are displayed in online supplementary table S2 in the online supplementary.

\section{Lung function decline associated with increasing exacerbation rates}

Patients treated with or without ICS

This analysis included 14572 patients who were treated with ICS and 4867 without ICS as the highest level of therapy during follow-up. Patients with higher annual rates of exacerbations after initiation of ICS-containing therapy had a significantly faster $\mathrm{FEV}_{1}$ decline $(5.8 \mathrm{~mL} /$ year per one unit increase in annual exacerbation rate $(95 \% \mathrm{CI} 4.9$ to 6.6$), \mathrm{p}<0.0001)$. This was similar for patients on non-ICS containing therapy $(5.7 \mathrm{~mL} /$ year (3.6 to 7.7 ), $\mathrm{p}<0.0001$; figure 3 ).
Patients with $B E C \geq 350$ cells/ $\mu L$, stratified by therapy

Subsequent analyses included 12178 patients with BEC available (414 with $<50,9372$ with $50-349$ and 2392 with $\geq 350$ cells/ $\mu \mathrm{L})$. The lowest absolute level of lung function decline was seen in patients with a BEC $\geq 350$ cells $/ \mu \mathrm{L}$ who did not experience any exacerbation following therapy initiation even though they never received an ICS prescription $(31.9 \mathrm{~mL} /$ year $(95 \% \mathrm{CI}$ 26.5 to 37.2); figure 4). However, when patients with a BEC $\geq 350$ cells $/ \mu \mathrm{L}$ experienced exacerbations while not treated with ICS, a substantial excess decline of $19.4 \mathrm{~mL} /$ year $(95 \%$ CI 12.0 to $26.7, p<0.0001$ ) with every increase of one exacerbation per year was observed (figure 4C). This excess decline associated with increasing exacerbation rate was reduced by $15.1 \mathrm{~mL} / \mathrm{year}$ (6.6 to 23.6 ) to $4.3 \mathrm{~mL} /$ year ( 1.9 to $6.7, \mathrm{p}<0.0001$ ) in those with a BEC $\geq 350$ cells $/ \mu \mathrm{L}$ treated with ICS (figure $4 \mathrm{C}$ ). Sensitivity analyses including patients with at least five available $\mathrm{FEV}_{1}$ measurements $(\mathrm{n}=9276 ; 7024$ ICS, 2252 non-ICS) showed similar results; a significant excess $\mathrm{FEV}_{1}$ decline of $16.1 \mathrm{~mL} / \mathrm{year}$ (95\% CI 8.0 to $24.1, \mathrm{p}<0.0001$ ) was evident with every increase of one exacerbation per year in patients with BECs $\geq 350$ cells/ $\mu \mathrm{L}$ who were not treated with ICS (online supplementary figure S1).

Patients with BEC 50-349 cells/ $\mu \mathrm{L}$, stratified by therapy Significant excess lung function decline associated with increasing exacerbation rates was not seen in patients with a BEC of $50-349$ cells $/ \mu \mathrm{L}$ who did not receive ICS $(2.3 \mathrm{~mL} /$ year $(95 \% \mathrm{CI}$ -0.7 to 5.4$), p=0.1370$; figure $4 \mathrm{~B}$ ), but was present and significantly $(\mathrm{p}=0.0060)$ greater for patients who were treated with ICS $(6.7 \mathrm{~mL} /$ year (5.3 to 8.0$), \mathrm{p}<0.0001$; figure $4 \mathrm{~B})$.

\section{Patients with $\mathrm{BEC}<50$ cells/ $\mu \mathrm{L}$, stratified by ICS therapy}

The association between exacerbation rate and excess decline in patients with eosinopenia was not significantly different from that observed in patients with a BEC of $50-349$ cells $/ \mu \mathrm{L}$ ( $\mathrm{p}$ value interaction term $=0.5334$ for patients on ICS and 0.8100 for patients not treated with ICS; figure 4A).

\section{Eosinophil cut-off points of 250 and 450 cells $/ \mu \mathrm{L}$}

A lower BEC cut-off point of 250 cells $/ \mu \mathrm{L}$ did not result in any significant effect modification. Using a higher cut-off point of 450 cells $/ \mu \mathrm{L}$ resulted in significant effect modification by the $\mathrm{BEC}$ of the association between exacerbations and decline among patients treated with ICS, which was not significant $(p=0.096)$ when using a cut-off point of 350 cells $/ \mu \mathrm{L}$. The association was non-significant for patients treated with ICS with a BEC $\geq 450$ cells $/ \mu \mathrm{L}(1.0 \mathrm{~mL} /$ year $(95 \% \mathrm{CI}-2.5$ to 4.5$), \mathrm{p}=0.5662$; online supplementary figure S2 in online supplementary). See online supplementary tables $\mathrm{S} 3-\mathrm{S} 6$ in the online supplementary for details of regression coefficients for the models reported.

\section{Exclusion of patients ever diagnosed with asthma}

In patients with a $\mathrm{BEC} \geq 350$ cells $/ \mu \mathrm{L}$ who were never diagnosed with asthma and never received prescriptions for ICS, an excess decline of $18.8 \mathrm{~mL} /$ year $(95 \%$ CI 11.4 to $26.2, \mathrm{p}<0.0001)$ with every increase of one exacerbation per year was also evident (see online supplementary figure S3 in online data supplementary).

\section{Adherence}

Patients with $<50 \%$ (low level) adherence who were receiving ICS had significantly more decline than patients with $80 \%-100 \%$ (good) adherence (difference $=5.1 \mathrm{~mL} /$ year $(95 \%$ CI 1.9 to 8.3$)$, $\mathrm{p}=0.0017)$. In patients not treated with ICS, poor adherence 


\section{Chronic obstructive pulmonary disease}

Table 3 Demographic and clinical characteristics of patients treated with or without ICS as the highest level of therapy during follow-up

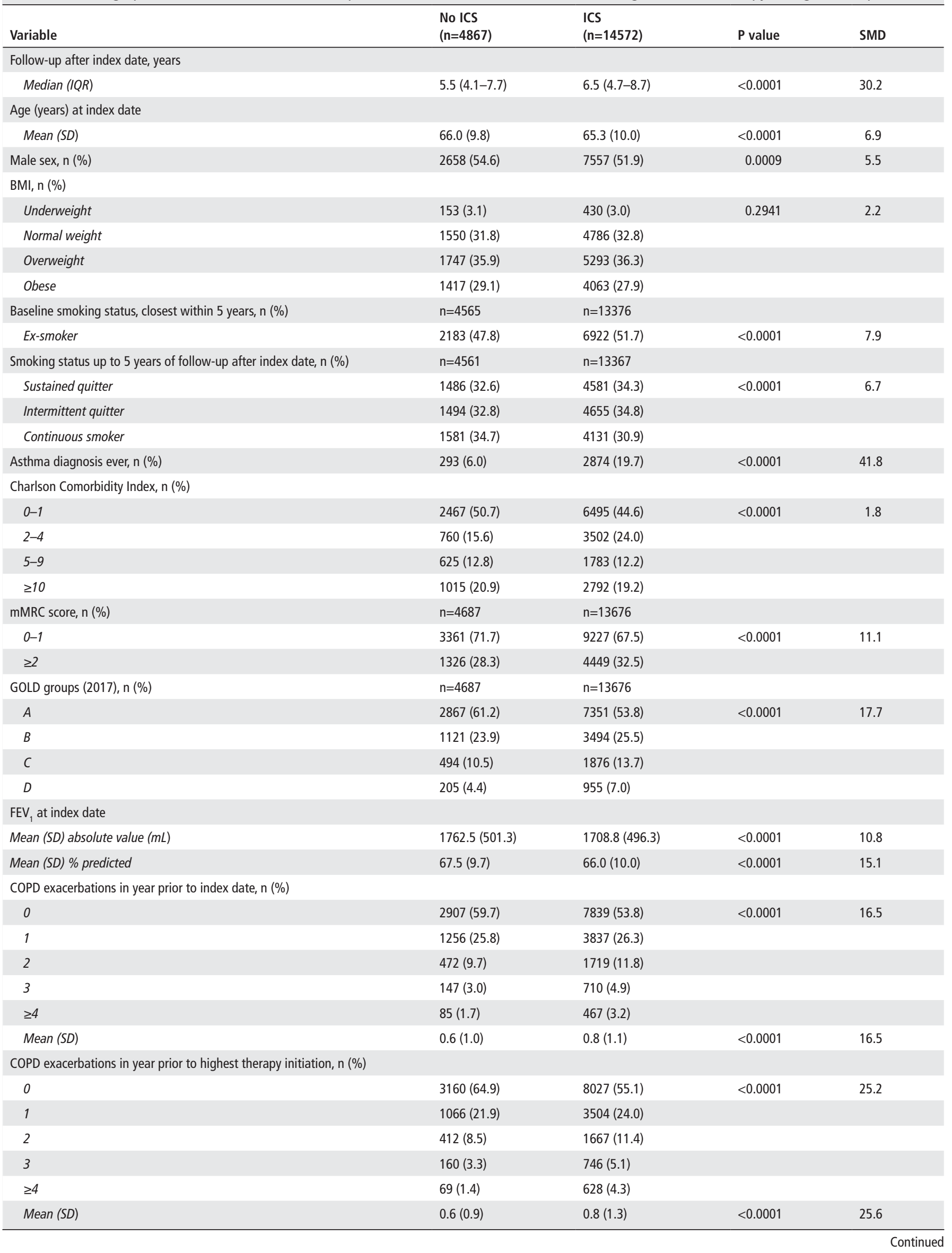


Table 3 Continued

\begin{tabular}{|c|c|c|c|c|}
\hline Variable & $\begin{array}{l}\text { No ICS } \\
(n=4867)\end{array}$ & $\begin{array}{l}\text { ICS } \\
(n=14572)\end{array}$ & $P$ value & SMD \\
\hline \multicolumn{5}{|c|}{$\begin{array}{l}\text { COPD exacerbations, annual rate after initiation of highest therapy, rounded, } \mathrm{n} \\
(\%)\end{array}$} \\
\hline 0 & $3635(74.7)$ & $8822(60.5)$ & $<0.0001$ & 31.2 \\
\hline 1 & $946(19.4)$ & $4001(27.5)$ & & \\
\hline 2 & $196(4.0)$ & 1039 (7.1) & & \\
\hline 3 & $55(1.1)$ & $369(2.5)$ & & \\
\hline$\geq 4$ & $35(0.7)$ & $341(2.3)$ & & \\
\hline Mean (SD) & $0.4(0.7)$ & $0.6(1.0)$ & & \\
\hline
\end{tabular}

BMI, body mass index; ICS, inhaled corticosteroid; mMRC, modified Medical Research Council; P, p value for the Kruskal-Wallis equality-of-populations rank test, or the Pearson's chi-square test of independent categories, where appropriate; SMD, standardised mean difference.

to long-acting bronchodilators was also associated with more decline (9.4 (95\% CI 3.1 to 15.6), $\mathrm{p}=0.0035)$. See online supplementary figure S4 in online data supplementary.

\section{DISCUSSION}

This study is one of the first to examine the effect of COPD exacerbations on lung function decline taking into account the use of maintenance therapy and BEC. Our results suggest that an individual with repeated exacerbations and a high $\mathrm{BEC}$ who is not on ICS therapy is subject to rapid lung function decline, which could be substantially reduced through ICS use. This novel and important observation addresses a very important need which is either not recognised or ignored and which has important potential consequences for patients with COPD.

Our results support the findings from post hoc analyses of the ISOLDE clinical trial in patients with more advanced COPD. ${ }^{19}$ In these post hoc analyses, the rate of annual $\mathrm{FEV}_{1}$ decline was significantly reduced in patients on fluticasone propionate compared with placebo when blood eosinophil levels were $\geq 2 \%$, but not when they were less than $2 \%$. Our results highlight the importance of identifying patients who have COPD exacerbations as well as a high level of blood eosinophils in daily clinical practice. This is key, as preventing exacerbations at an early stage could slow COPD progression and the risk of developing severe disease, and thus represents an important window of opportunity for treatment. This approach is not considered in current treatment paradigms for COPD.

A few other studies have reported that increased exacerbations result in accelerated lung function decline in those with severe to moderate disease. ${ }^{911}$ More recently, accelerated decline in lung function following acute exacerbations $(23 \mathrm{~mL} /$ year $(95 \%$ CI 2 to 44 ) per exacerbation) has been reported particularly in those with mild disease. ${ }^{12}$ The latter was however estimated from a relatively small number of patients with infrequent ICS use $(13 \%)$. We confirm these findings in our study population of patients with mild to moderate airflow limitation.

An important conclusion from our study is that patients with a BEC of $\geq 350$ cells $/ \mu \mathrm{L}$ who continue to have exacerbations under treatment with long-acting bronchodilators need additional treatment with ICS to prevent excess decline associated with these exacerbations. A recently published observational study reported beneficial effects of prevalent ICS use on lung function decline, regardless of BEC using a cut-off point of $\geq 150$ cells $/ \mu \mathrm{L} .^{22}$ In addition, their results suggest that new ICS users with a high BEC may benefit more than those with a low BEC when first started on ICS. However, they did not consider the exacerbation rate occurring under maintenance therapy. Our findings are in line with current GOLD recommendations (introduced in 2019 after our data collection) and provide further evidence to support the use of ICS therapy in patients with high BECs and a pattern of repeated exacerbations. It should be noted that in our study exacerbations were defined by the need for acute treatment, usually with OCS. Most randomised controlled trials use symptom-based algorithms which may catch different types of exacerbations, such as bouts of bronchitis, and these may be associated with lung function decline in a different way. ${ }^{23}$ However, validation work has shown that symptom codes in UK electronic medical records have a very low sensitivity for detecting acute exacerbations of COPD and most of the codes will probably overlap with OCS or antibiotics therapy. ${ }^{24}$

We have previously shown that elevated BECs are associated with increased exacerbation rates. ${ }^{25}$ Previous studies suggest that a higher BEC is associated with improved response to ICS-containing therapies in COPD patients with a history of exacerbations. ${ }^{326}$ Chronic eosinophilic inflammation has been associated with tissue remodelling and fibrosis in a number of chronic T-helper 2-mediated diseases, including asthma. This may manifest itself by occurrence of exacerbations, which may be triggered by external factors, such as a viral infection. ${ }^{27}$ Our results suggest that a high BEC is a useful marker of risk for more severe exacerbations in a substantial subset of the COPD population who also require ICS to reduce inflammationdriven tissue remodelling to prevent irreversible tissue damage and progression of disease. Low overall adherence to maintenance therapy was associated with more lung function decline, further supporting the beneficial effects of maintenance therapy on lung function.

Within the group of patients treated with ICS-containing therapy in our study, no relevant impact of exacerbations occurring after initiation of ICS on decline was found in patients with a $\mathrm{BEC} \geq 450$ cells $/ \mu \mathrm{L}$. This provides evidence of a distinct phenotype associated with frequent exacerbations causing accelerated lung function decline when not treated with ICS. ${ }^{25}$

The strengths of our study include the large sample size, long follow-up and high number of spirometry measurements most patients underwent. To evaluate the impact of less accurate estimates of lung function decline in patients with few measurements, we performed a sensitivity analysis excluding patients with less than five available measurements and found similar results. In 2017, three-quarters of patients with COPD in the UK general population had $\mathrm{FEV}_{1}$ recorded. Repeated spirometry is recommended as standard COPD management in general practice in the UK within 
Table 4 Demographic and clinical characteristics of patients by blood eosinophil count recorded closest to initiation of the highest level of maintenance therapy

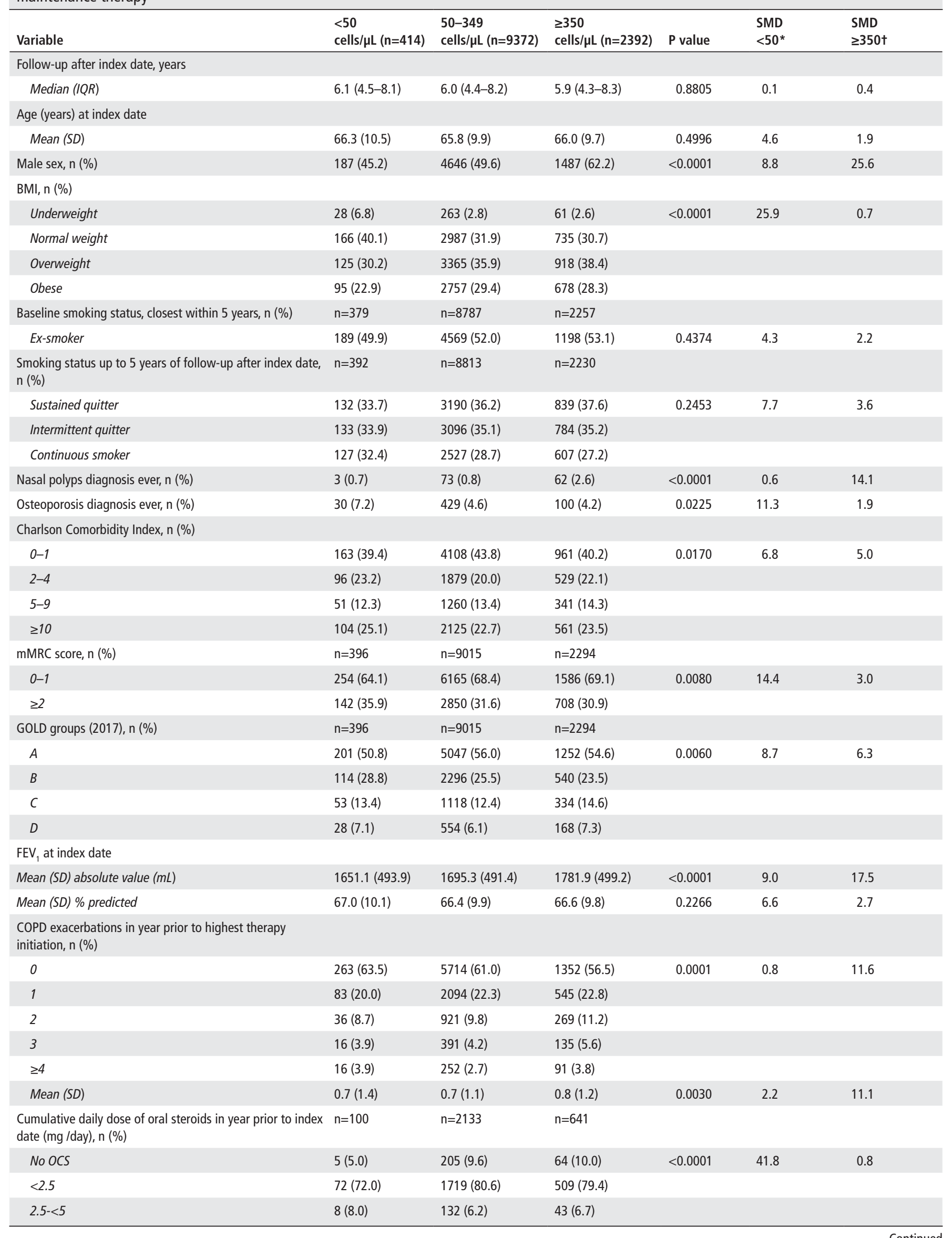




\begin{tabular}{|c|c|c|c|c|c|c|}
\hline Variable & $\begin{array}{l}<50 \\
\text { cells/ } \mu \mathrm{L}(\mathrm{n}=414)\end{array}$ & $\begin{array}{l}50-349 \\
\text { cells/ } / \mu \mathrm{L}(\mathrm{n}=9372)\end{array}$ & $\begin{array}{l}\geq 350 \\
\text { cells/ } \mu \mathrm{L}(\mathrm{n}=2392)\end{array}$ & $P$ value & $\begin{array}{l}\text { SMD } \\
<50^{*}\end{array}$ & $\begin{array}{l}\text { SMD } \\
\geq 350 \dagger\end{array}$ \\
\hline $5-7.5$ & $8(8.0)$ & $33(1.5)$ & $13(2.0)$ & & & \\
\hline$\geq 7.5$ & $7(7.0)$ & $44(2.1)$ & $12(1.9)$ & & & \\
\hline \multicolumn{7}{|c|}{$\begin{array}{l}\text { GP consultations, all-cause, number in year prior to index } \\
\text { date, } \mathrm{n}(\%)\end{array}$} \\
\hline $0-1$ & $0(0.0)$ & $49(0.5)$ & $16(0.7)$ & 0.0189 & 21.0 & 0.9 \\
\hline $2-4$ & $25(6.0)$ & $679(7.2)$ & $177(7.4)$ & & & \\
\hline $5-8$ & $63(15.2)$ & $1950(20.8)$ & $486(20.3)$ & & & \\
\hline $9-13$ & $110(26.6)$ & $2515(26.8)$ & $657(27.5)$ & & & \\
\hline $14-17$ & $59(14.3)$ & 1505 (16.1) & $379(15.8)$ & & & \\
\hline $18-22$ & $66(15.9)$ & $1184(12.6)$ & $306(12.8)$ & & & \\
\hline $23+$ & $91(22.0)$ & 1490 (15.9) & 371 (15.5) & & & \\
\hline
\end{tabular}

*As compared with the $50-349$ cells $/ \mu$ L category.

†As compared with the $50-349$ cells/ $\mu \mathrm{L}$ category.

BMI, body mass index; GP, general practitioner; mMRC, modified Medical Research Council; P, p value for the Kruskal-Wallis equality-of-populations rank test, or the Pearson's chi-square test of independent categories, where appropriate; SMD, standardised mean difference.

the $\mathrm{QOF}^{28}$ All available $\mathrm{FEV}_{1}$ values for patients were included in the analyses as we saw no reason to exclude values prior to the actual recording of a diagnosis, which may happen at any time over the course of COPD. A sensitivity analysis which excluded FEV recordings prior to COPD diagnosis gave similar results (data not shown). A further strength of this study is that primary care data are used and thus the results are generalisable to the wider COPD population. Most studies that have assessed the role of BEC in the context of COPD are clinical trials. Finally, similar results were obtained when patients with a history of asthma were excluded from the analyses, showing no impact on the conclusions even if there was some misclassification between COPD and asthma.

Possible limitations of our study also need consideration. First, data in the OPCRD and CPRD are collected for clinical and routine use rather than specifically for research purposes. Quality control and validity checks of spirometry are conducted at the practice level with quality of spirometry undertaken in UK primary care generally high; however, the lack of standardisation across practices may have affected the accuracy of measurements. ${ }^{29}$ Also, it is

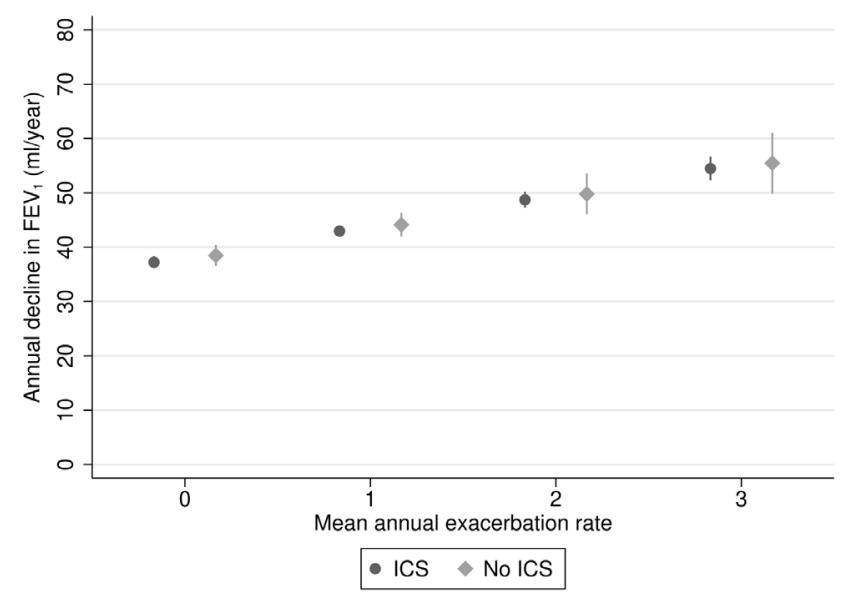

Figure 3 Impact of annual exacerbation rate on annual $\mathrm{FEV}_{1}$ decline following initiation of the highest level of therapy for patients receiving ICS and patients not receiving ICS. Error bars represent the $95 \% \mathrm{Cl}$ of the mean FEV decline. ICS, inhaled corticosteroid. unclear whether most of the spirometry measurements in our study were conducted pre-bronchodilator or post-bronchodilator, which may have resulted in some bias. It is recommended in the UK that diagnostic spirometry only be performed by an operator trained and assessed to the standards of the Association for Respiratory Technology and Physiology or equivalent, and that spirometry is carried out to the standards of the British Thoracic Society. This is to ensure delivery of high-quality diagnostic spirometry in primary care. ${ }^{30}$ Both data sources used for this study include dynamic populations of patients diagnosed with COPD. Follow-up time in the GP practice therefore varies between patients, mostly in an unbiased way. We assumed that patients with $\geq 3$ years of spirometry follow-up were representative of all patients with COPD whose disease was managed by a GP. This assumption is tenable because spirometry should be performed annually within the QOF, an incentive programme for all GP practices in the UK to improve quality of care. However, it is unclear how the frequency with which FEV, measurements are taken is related to disease progression despite the precision of effect sizes in our models increasing with an increasing number of lung function measurements. Second, a reduction in exacerbation rate may be the underlying mechanism of action of ICS-containing therapies, and exacerbations occurring despite therapy may have different effects on lung function decline than
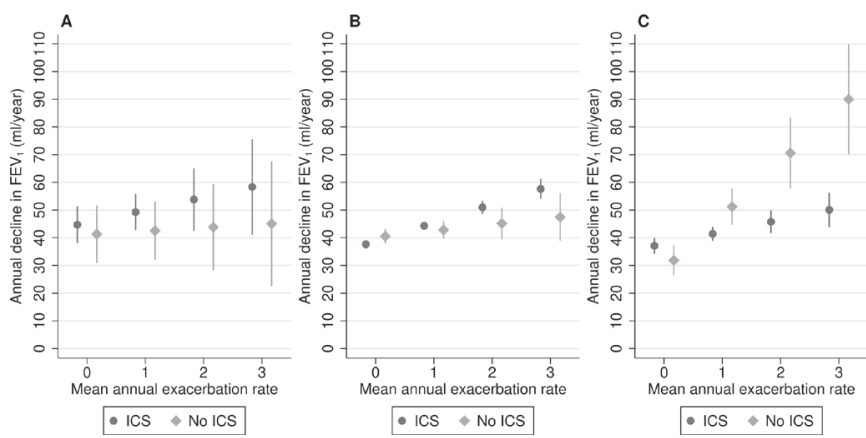

Figure 4 Impact of annual exacerbation rate on annual FEV decline in patients receiving ICS and patients not receiving ICS by blood eosinophil count. Error bars represent the $95 \% \mathrm{Cl}$ of the mean $\mathrm{FEV}_{1}$ decline. (A) Blood eosinophil count $<50$ cells $/ \mu \mathrm{L}$. (B) Blood eosinophil count 50-349 cells/ $\mu \mathrm{L}$. (C) Blood eosinophil count $\geq 350$ cells $/ \mu \mathrm{L}$. 
exacerbations that were prevented. It is also possible that patients on ICS receive better general care, visit their GP more often and have more spirometry readings; however, in our study, there were no relevant differences in GP consultations in the baseline year, neither for COPD-related nor for all-cause consultations, between ICS and non-ICS populations (online supplementary table S1). We were limited in our ability to model the effect of adherence (those doing worse are more likely to be adherent) and perhaps underestimated the benefit of treatment with ICS. Another limitation is that information on the occurrence of hospital admissions for COPD exacerbation was based on GP records, which has been reported to have low sensitivity for detecting events in the CPRD. ${ }^{31}$ This may have caused some (non-differential) misclassification bias of the mean rate of COPD exacerbations over time. A further limitation is that in $1 \%$ of patients, the exacerbation rate had to be estimated over a short period of 6-12 months which may have underestimated the exacerbation rate during total spirometry follow-up; however, it is unlikely that this significantly influenced the results. Also, BECs are not recorded routinely in general practice, which may have influenced the extent to which the study population is representative of the overall COPD population. In addition, BECs may vary over time and associations may have been different if this was taken into account. ${ }^{32}$ The blood eosinophil cut-off points used in our study were based on the recording of the original data and were not as defined in current GOLD recommendations; however, it is thought this would have minimal effect on the results. Finally, there is a possibility of residual confounding associated with the observational study design despite analyses being adjusted for wellknown independent risk factors of lung function decline.

In conclusion, some patients with COPD experience progressive lung function decline. We have previously demonstrated that a high $\mathrm{BEC}$ is associated with a higher risk of exacerbations. ${ }^{25}$ Although firm conclusions cannot be drawn from our hypothesis-generating study, the results suggest that exacerbations in patients with eosinophilic inflammation of the airways influence the progression of COPD especially when the patient is not on ICS. An individual with repeated exacerbations and a high BEC but not on ICS therapy may be subject to faster lung function decline. ICS-containing therapies in these patients could attenuate lung function decline, but more research is needed to confirm this. We recommend a lung function assessment in patients aged $>35$ years with a high BEC and repeated prescriptions for oral steroids as ICS intervention in these cases may change the course of COPD at the early stages.

\author{
Author affiliations \\ 1 Observational and Pragmatic Research Institute, Singapore \\ ${ }^{2}$ AstraZeneca, Durham, North Carolina, USA \\ ${ }^{3}$ AstraZeneca, Gothenburg, Sweden \\ ${ }^{4}$ Department of Medical Epidemiology and Biostatistics, Karolinska Institute, \\ Stockholm, Sweden \\ ${ }^{5}$ AstraZeneca, 280 Headquarters Plaza, East Tower, Morristown, NJ 07960, USA \\ ${ }^{6}$ General Practitioners Research Institute, Groningen, The Netherlands \\ ${ }^{7}$ Respiratory Evaluation Sciences Program, Faculty of Pharmaceutical Sciences, \\ University of British Columbia, Vancouver, British Columbia, Canada \\ ${ }^{8}$ Centre for Heart Lung Innovation, St. Paul's Hospital, Vancouver, British Columbia, \\ Canada \\ ${ }^{9}$ Centre of Academic Primary Care, Division of Applied Health Sciences, University of \\ Aberdeen, Aberdeen, UK
}

\section{Twitter Mohsen Sadatsafavi @mo_safavi}

Acknowledgements Writing and editorial support was provided by Dr Julia Granerod, supported by the Observational and Pragmatic Research Institute Pte. Ltd (OPRI).

Contributors DBP and MK led the study design process, and all authors provided input into the research design. MK was responsible for data acquisition and analyses. MS provided statistical advice based on previous work (Zafari et al, CMAJ, 2016). MK developed the first draft of the manuscript. All authors contributed to the interpretation of the data, reviewed and edited drafts of the manuscript, and approved the final draft of the manuscript for submission.

Funding This study was funded by AstraZeneca.

Competing interests MK, JV, VC and JWHK are employees of the Observational and Pragmatic Research Institute, which conducted this study and which has conducted paid research in respiratory disease on behalf of the following other organisations in the past 5 years: Aerocrine, AKL Research and Development Ltd, Almirall, AstraZeneca, Boehringer Ingelheim, Chiesi, GlaxoSmithKline, Mylan, Mundipharma, Napp, Novartis, Orion, Takeda, Teva, Zentiva (a Sanofi company). DBP has board membership with Aerocrine, Amgen, AstraZeneca, Boehringer Ingelheim, Chiesi, Mylan, Mundipharma, Napp, Novartis, Regeneron Pharmaceuticals, Sanofi Genzyme, Teva Pharmaceuticals; consultancy agreements with Almirall, Amgen, AstraZeneca, Boehringer Ingelheim, Chiesi, GlaxoSmithKline, Mylan, Mundipharma, Napp, Novartis, Pfizer, Teva Pharmaceuticals, Theravance; grants and unrestricted funding for investigator-initiated studies (conducted through Observational and Pragmatic Research Institute Pte Ltd) from Aerocrine, AKL Research and Development Ltd, AstraZeneca, Boehringer Ingelheim, British Lung Foundation, Chiesi, Mylan, Mundipharma, Napp, Novartis, Pfizer, Regeneron Pharmaceuticals, Respiratory Effectiveness Group, Sanofi Genzyme, Teva Pharmaceuticals, Theravance, UK National Health Service, Zentiva (Sanofi Generics); payment for lectures/speaking engagements from Almirall, AstraZeneca, Boehringer Ingelheim, Chiesi, Cipla, GlaxoSmithKline, Kyorin, Mylan, Merck, Mundipharma, Novartis, Pfizer, Regeneron Pharmaceuticals, Sanofi Genzyme, Skyepharma, Teva Pharmaceuticals; payment for manuscript preparation from Mundipharma, Teva Pharmaceuticals; payment for the development of educational materials from Mundipharma, Novartis; payment for travel/accommodation/meeting expenses from Aerocrine, AstraZeneca, Boehringer Ingelheim, Mundipharma, Napp, Novartis, Teva Pharmaceuticals; funding for patient enrolment or completion of research from Chiesi, Novartis, Teva Pharmaceuticals, Zentiva (Sanofi Generics); stock/stock options from AKL Research and Development Ltd which produces phytopharmaceuticals; owns $74 \%$ of the social enterprise Optimum Patient Care Ltd (Australia and UK) and 74\% of Observational and Pragmatic Research Institute Pte Ltd (Singapore); and is peer reviewer for grant committees of the Efficacy and Mechanism Evaluation programme, and Health Technology Assessment. CC, PD and PD are employees of AstraZeneca. DDS has received honoraria for speaking engagements from Boehringer Ingelheim (BI), AstraZeneca (AZ) and Novartis. He has received research funding from Merck, BI and $A Z$ for work related to COPD and has sat on advisory boards of $A Z, B I$ and Sanofi. MS has received honoraria for speaking engagements from Boehringer Ingelheim, AstraZeneca and GlaxoSmithKline.

Patient consent for publication Not required.

Provenance and peer review Not commissioned; externally peer reviewed.

Data availability statement The dataset supporting the conclusions of this article was derived from the Clinical Practice Research Datalink (www.cprd.com) and the Optimum Patient Care Research Database (www.opcrd.co.uk). The CPRD has broad National Research Ethics Service Committee (NRES) ethics approval for purely observational research using the primary care data and established data linkages. The OPCRD has ethical approval from the National Health Service (NHS) Research Authority to hold and process anonymised research data (Research Ethics Committee reference: 15/EM/0150). This study was approved by the Anonymised Data Ethics Protocols and Transparency (ADEPT) committee - the independent scientific advisory committee for the OPCRD, and the Independent Scientific Advisory Committee (ISAC) for the CPRD. The authors do not have permission to give public access to the study dataset; researchers may request access to CPRD or OPCRD data for their own purposes. Access to CPRD can be made via the CPRD website (https://www.cprd.com/researcher/) or via the enquiries email enquiries@cprd. com. Access to OCPRD can be made via the OCPRD website (https://opcrd.co.uk/ our-database/data-requests/) or via the enquiries email info@opcrd.co.uk. The study was designed, implemented, and registered in accordance with the criteria of the European Network of Centres for Pharmacoepidemiology and Pharmacovigilance (EUPAS19879).

Open access This is an open access article distributed in accordance with the Creative Commons Attribution Non Commercial (CC BY-NC 4.0) license, which permits others to distribute, remix, adapt, build upon this work non-commercially, and license their derivative works on different terms, provided the original work is properly cited, appropriate credit is given, any changes made indicated, and the use is non-commercial. See: http://creativecommons.org/licenses/by-nc/4.0/.

\section{ORCID iDs}

Mohsen Sadatsafavi http://orcid.org/0000-0002-0419-7862

David B Price http://orcid.org/0000-0002-9728-9992

\section{REFERENCES}

1 Global Initiative for Chronic Obstructive Lung Disease. Pocket guide to COPD diagnosis, management, and prevention - a guide for health care professionals, 2016. 
2 Lange P, Celli B, Agustí A, et al. Lung-function trajectories leading to chronic obstructive pulmonary disease. N Engl J Med 2015;373:111-22.

3 Global Initiative for Chronic Obstructive Lung Disease (GOLD). From the global strategy for the diagnosis, management and prevention of COPD, 2017. Available: https://goldcopd.org

4 Tantucci C, Modina D. Lung function decline in COPD. Int J Chron Obstruct Pulmon Dis 2012;7:95-9.

5 Bhatt SP, Soler X, Wang $X$, et al. Association between functional small airway disease and FEV1 decline in chronic obstructive pulmonary disease. Am J Respir Crit Care Med 2016;194:178-84

6 Sohal SS, Soltani A, Reid D, et al. A randomized controlled trial of inhaled corticosteroids (ICS) on markers of epithelial-mesenchymal transition (EMT) in large airway samples in COPD: an exploratory proof of concept study. Int I Chron Obstruct Pulmon Dis 2014;9:533-42.

7 Bhowmik A, Seemungal TA, Sapsford RJ, et al. Relation of sputum inflammatory markers to symptoms and lung function changes in COPD exacerbations. Thorax 2000:55:114-20.

8 Crooks SW, Bayley DL, Hill SL, et al. Bronchial inflammation in acute bacterial exacerbations of chronic bronchitis: the role of leukotriene B4. Eur Respir $J$ 2000;15:274-80.

9 Anzueto A. Impact of exacerbations on COPD. Eur Respir Rev 2010;19:113-8.

10 Decramer M, Celli B, Kesten S, et al. Effect of tiotropium on outcomes in patients with moderate chronic obstructive pulmonary disease (UPLIFT): a prespecified subgroup analysis of a randomised controlled trial. Lancet 2009;374:1171-8.

11 Celli BR, Thomas NE, Anderson JA, et al. Effect of pharmacotherapy on rate of decline of lung function in chronic obstructive pulmonary disease: results from the torch study. Am J Respir Crit Care Med 2008;178:332-8.

12 Dransfield MT, Kunisaki KM, Strand MJ, et al. Acute exacerbations and lung function loss in smokers with and without chronic obstructive pulmonary disease. Am J Respir Crit Care Med 2017;195:324-30.

13 Sadatsafavi M, Xie H, Etminan M, et al. The association between previous and future severe exacerbations of chronic obstructive pulmonary disease: updating the literature using robust statistical methodology. PLoS One 2018;13:e0191243.

14 Siddiqui SH, Pavord ID, Barnes NC, et al. Blood eosinophils: a biomarker of COPD exacerbation reduction with inhaled corticosteroids. Int I Chron Obstruct Pulmon Dis 2018;13:3669-76

15 Ferguson GT, Rabe KF, Martinez FJ, et al. Triple therapy with budesonide/ glycopyrrolate/formoterol fumarate with co-suspension delivery technology versus dual therapies in chronic obstructive pulmonary disease (KRONOS): a double-blind parallel-group, multicentre, phase 3 randomised controlled trial. Lancet Respir Med 2018:6:747-58.

16 Bafadhel M, McKenna S, Terry S, et al. Blood eosinophils to direct corticosteroid treatment of exacerbations of chronic obstructive pulmonary disease: a randomized placebo-controlled trial. Am J Respir Crit Care Med 2012;186:48-55.
17 Pascoe S, Locantore N, Dransfield MT, et al. Blood eosinophil counts, exacerbations, and response to the addition of inhaled fluticasone furoate to vilanterol in patients with chronic obstructive pulmonary disease: a secondary analysis of data from two parallel randomised controlled trials. Lancet Respir Med 2015;3:435-42.

18 Bafadhel M, Pavord ID, Russell REK. Eosinophils in COPD: just another biomarker? Lancet Respir Med 2017:5:747-59.

19 Barnes NC, Sharma R, Lettis $S$, et al. Blood eosinophils as a marker of response to inhaled corticosteroids in COPD. Eur Respir J 2016;47:1374-82.

20 Data Care Solutions. Quality and outcomes framework codes, 2018. Available: https://www.datacaresolutions.co.uk/qof-codes\#Chronic-Obstructive-PulmonaryDisease

21 Quint JK, Müllerova H, DiSantostefano RL, et al. Validation of chronic obstructive pulmonary disease recording in the clinical practice research Datalink (CPRD-GOLD) BMJ Open 2014;4:e005540.

22 Whittaker HR, Müllerova H, Jarvis D, et al. Inhaled corticosteroids, blood eosinophils, and FEV , decline in patients with COPD in a large UK primary health care setting. Int $J$ Chron Obstruct Pulmon Dis 2019;14:1063-73.

23 Trappenburg JCA, van Deventer AC, Troosters T, et al. The impact of using different symptom-based exacerbation algorithms in patients with COPD. Eur Respir J 2011;37:1260-8

24 Rothnie KJ, Müllerová H, Hurst JR, et al. Validation of the recording of acute exacerbations of COPD in UK primary care electronic healthcare records. PLoS One 2016;11:e0151357.

25 Kerkhof M, Sonnappa S, Postma DS, et al. Blood eosinophil count and exacerbation risk in patients with COPD. Eur Respir J 2017;50:1700761.

26 Brusselle G, Pavord ID, Landis S, et al. Blood eosinophil levels as a biomarker in COPD. Respir Med 2018;138:21-31.

27 Fehrenbach H, Wagner C, Wegmann M. Airway remodeling in asthma: what really matters. Cell Tissue Res 2017;367:551-69.

28 NHS Digital. Quality and outcomes framework, 2017. Available: https://digital.nhs. uk/data-and-information/publications/statistical/quality-and-outcomes-frameworkachievement-prevalence-and-exceptions-data

29 Rothnie KJ, Chandan JS, Goss HG, et al. Validity and interpretation of spirometric recordings to diagnose COPD in UK primary care. Int J Chron Obstruct Pulmon Dis 2017:12:1663-8.

30 Primary Care Commissioning. A guide to performing quality assured diagnostic spirometry, 2013. Available: https://www.brit-thoracic.org.uk/document-library/ delivery-of-respiratory-care/spirometry/guide-to-performing-diagnostic-spirometry-( 2013)/

31 Rothnie KJ, Müllerová H, Thomas SL, et al. Recording of hospitalizations for acute exacerbations of COPD in UK electronic health care records. Clin Epidemiol 2016;8:771-82.

32 Landis SH, Suruki R, Hilton E, et al. Stability of blood eosinophil count in patients with COPD in the UK clinical practice research Datalink. COPD 2017;14:382-8. 